\title{
SYSTEM FOR CHANGING THE RADIAL RESPONSE ON CAR WHEELS
}

\author{
Petr Jilek ${ }^{1}$, Jan Němec ${ }^{1}$ \\ ${ }^{1}$ Department of Transport Means and Diagnostics, Faculty of Transport Engineering, University of Pardubice, \\ Studentská 95, 53210 Pardubice, Czech Republic
}

Link to this article: https://doi.org/10.11118/actaun202068010039

Received: 2. 7. 2019, Accepted: 7. 2. 2020

To cite this article: JILEK PETR, NĚMEC JAN. 2020. System for Changing the Radial Response on Car Wheels. Acta Universitatis Agriculturae et Silviculturae Mendelianae Brunensis, 68(1): 39-47.

\begin{abstract}
The paper deals with the possibilities of change in adhesion force for experimental measurement on a road vehicle. The article deals with the ways in which the road vehicle can be brought to skid limit while driving at a safe speed. These are two newly designed systems (SlideWheel and Alternative SkidCar) to complement the experimental car. Both systems allow for the reduction of the adhesion force on car wheels, depending on the reduction of radial force transmitted by the car wheel. Their main difference is in the spatial arrangement and in the method of attachment to a car. The wheel units are mounted under the axles in case of SlideWheel and attached to the experimental car body via a subframe in case of Alternative SkidCar. We implemented an objective finding of their influence on the quantities describing the movement of the car in the two systems designed by the authors. Mutual comparison was made during experimental measurement during a test drive in the form of driving in a circle at a constant steering wheel turning angle. Experimental measurements were made with $50 \%$ of the radial response on car wheels. It is clear from the measured results that both systems met expectations and can be used to bring the car to the skid limit at a safe speed. Both systems help to induce any type of car skidding. The advantage of the SlideWheel system compared to Alternative SkidCar is its lower weight; the disadvantage is the size of the support wheels. The paper is focused on objective comparison of ASC and SW in terms of effect on the experimental car's behaviour.
\end{abstract}

Keywords: SlideWheel, SkidCar, adhesion force, experimental vehicle, stability

\section{INTRODUCTION}

More and more attention needs to be paid to safety nowadays when road traffic is increasing and cars are an integral part of our lives. The amount of cars will increase in the future, especially the autonomous ones. These are the cars that are still being retrofitted with new electronic systems. This is the area in which we need to look for new ways and conditions to test these systems before being put into production (Harun et al., 2016). Testing takes place first in the area of model preparation (Harun et al., 2016) and then experimental testing under modelled conditions is performed (Harun et al., 2016; Koštial et al., 2012). The process of testing electronic systems is complemented by continuous monitoring of characteristic quantities (Marek et al., 2016). The safety of road vehicles is given primarily by their stability. The crucial element of stability is the adhesion force, that is, the force transmitted between the car wheels and the road. If the limit value is exceeded, the balance of forces is violated and the car skids (Krmela et al., 2014). The speed at which the car skids is determined by the car structure, adhesion properties, driving style, car weight parameters (Reivaj et al., 2018; Verner et al., 2018), the state and condition of tyres and, last but not least, by proper maintenance (Glos et al., 2016; Sejkorová et al., 2017; Škarkan et al., 2018). The cars are mainly tested for lateral, longitudinal and directional stability. 
It would be ideal to use real conditions when testing cars. However, this area is limited due to the know-how of the car manufacturer, the safety of the operator or the conditions cannot be achieved. It is then necessary to proceed to the model conditions. One of the possibilities for reducing the adhesion force is to use a reduced adhesion coefficient of sliding surfaces (Lucete et al., 2017; Tesař et al., 2016) or sliding tyres (Albinsson et al., 2018; Gao et al., 2016).

The second option to reduce the adhesion force between the road and the car wheel is to reduce the radial response on the car wheels. The reduction can be achieved using additional wheels. This system is called SkidCar in the commercial sector. At present, it is necessary to test a unique experimental car at the authors' workplace, which has wheels of both turning axles at reduced adhesion.

Since the authors' workplace does not have a test corridor and surfaces to reduce adhesion, we developed and verified the functionality of the original device for changing the adhesion force. At the same time, we developed a measurement methodology to make the car skid while driving 'safely'. There are no authors dealing with the objective evaluation of the given adhesion issue in the literature.

\section{MATERIALS AND METHODS}

The main goal of the paper is to make the car skid at so-called 'safe speed'. We used a speed at which a potential accident does not have serious consequences and, at the same time, it is possible to objectively control the car to a limited extent based on the driver's experience. We selected a speed of $50 \mathrm{~km} / \mathrm{h}$ as the safe speed. Thus, the car must reach the skid limit when driving below the selected speed. To achieve the goal, we changed the size of the radial response on the car wheels. The reduction of the radial response is accomplished using four support units attached to the car.

\section{Alternative SkidCar}

Commercially sold SkidCar is a device that consists of a supporting frame, an electronic control system and a hydraulic circuit. The frame design is always single-purpose and is adapted to a given car without the possibility to use it on another type. In order to carry out experimental measurements on a customized car, we proceeded to the production of an analogue of commercial SkidCar. The frame is attached to the experimental car body. We placed the front wheel units with a crossbar behind the front axle; the rear crossbar with wheel units in front of rear axle. This is a deliberate placement to allow the car body to tilt more easily in the longitudinal direction. The change in the radial response of the car wheels is set before the experimental measurement. The setting is a mechanical ejection of the wheel unit. Based on the differences of our system from commercially available SkidCar, we call our system Alternative SkidCar (ASC) (Jilek et al., 2019); Fig. 1.

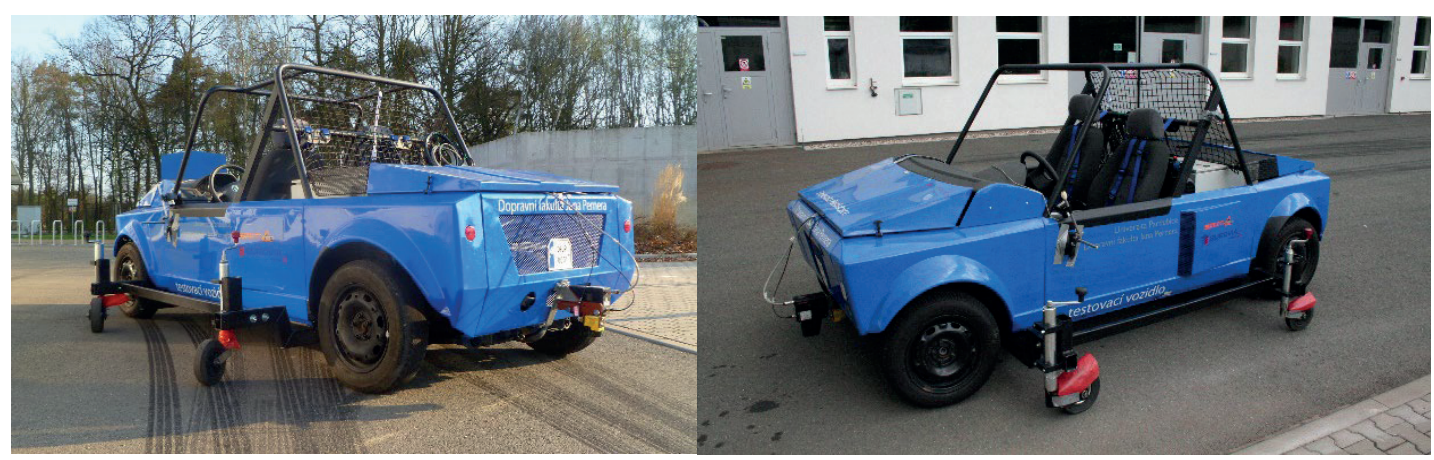

1: Experimental car with ASC (authors)

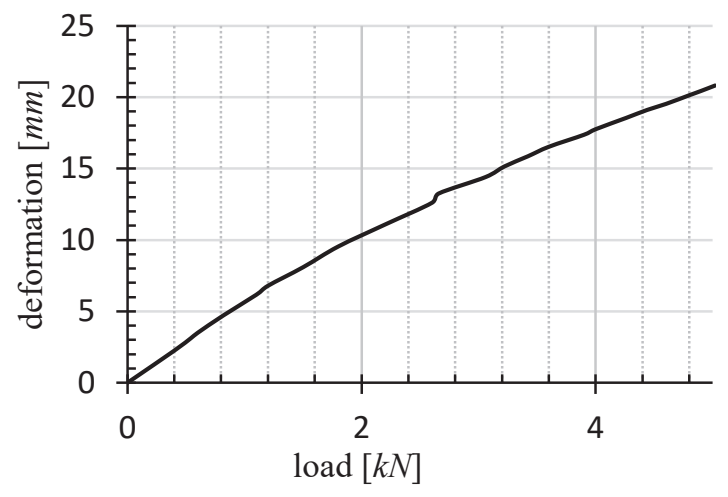

2: Deformation properties of ASC wheel units (authors)

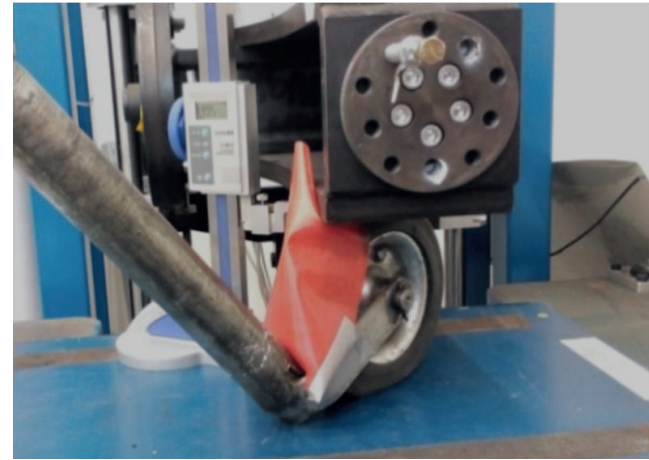

3: Measurement of ASC deformation properties on static adhesor (authors) 
The ASC frame is rigid enough and the movement of the body is limited by the rigidity of the support wheel units. The wheel unit flexibility is determined by the rigidity of bantam wheels.

The support wheel deformation properties (Fig. 2) were found on a static adhesor (Fig. 3) and are described by equation (1)

$y=-0.3441 x^{2}+5.8352 x$

When using ASC, the width of the experimental car increased by $845 \mathrm{~mm}$ to $2280 \mathrm{~mm}$ and the kerb weight increased by $198 \mathrm{~kg}$ to $1180 \mathrm{~kg}$.

\section{SlideWheel}

The alternative to ASC is the SlideWheel (SW) system designed by the authors. This is an additional device to complement the chassis of an experimental car (Fig. 4). It consists of an electrohydraulic system that allows the car to achieve different adhesion conditions. The system consists of four wheel units, a hydraulic unit with an electronic control circuit. The wheel unit consists of a hydraulic cylinder, a piston and a support wheel with an idler. The assembly is attached to the lower control arm. Applying pressure oil above the piston will reduce the radial response on the vehicle wheel. The hydraulic circuit filling control is controlled by electronics according to the operator's request. The fork creates a cotter for the support wheel. This allows the wheel unit to rotate when the direction of travel of the pattern is

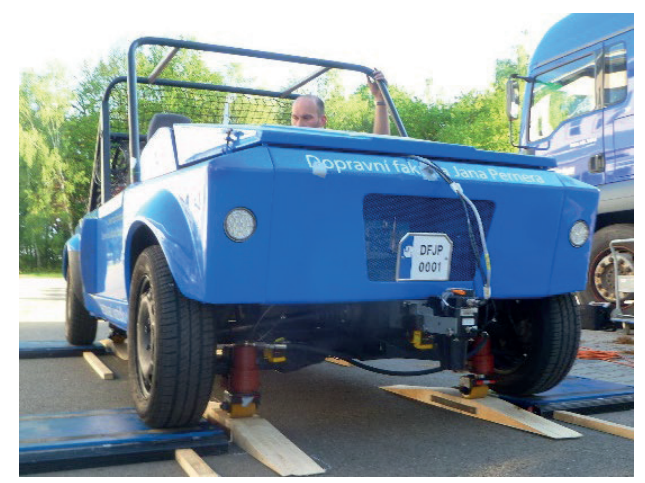

4: Experimental car with SW (authors)

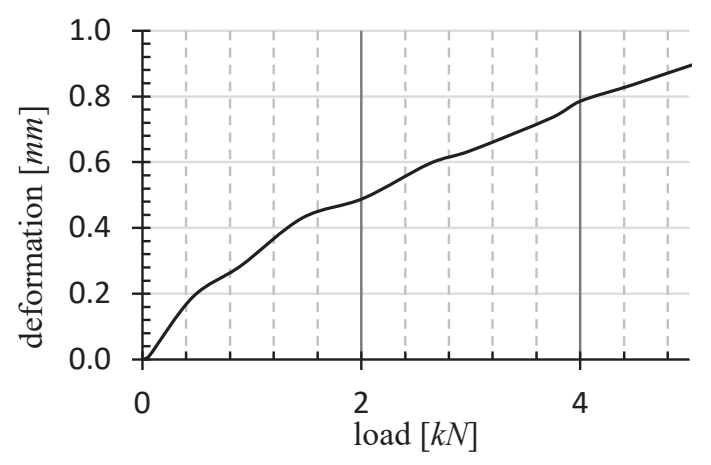

6: Deformation properties of SWwheel units (authors) changed. Each of the four electronically controlled hydraulic circuits allows partial lightening of any wheel. With a suitably selected combination, it is possible to lighten any axle or even a side of the car. The size of the change is within any range of radial responses. The SW system is designed directly for the experimental car.

The SW wheel units are attached to the experimental car through the lower McPherson axle arms. From this point of view, the SW system rigidity is given by the wheel unit rigidity. The support wheel deformation properties (Fig. 6) were found on a static adhesor (Fig. 7) and are described by equation (2).

$y=-0.0219 x^{2}+0.2873 x$

The noise emitted during driving increased due to the increase in the number of elements in contact with the road. The determination of the noise level increase is in (Kulička et al., 2016). Using SW, the curb weight of the experimental car increased by $68 \mathrm{~kg}$ to $1050 \mathrm{~kg}$.

\section{Experimental Measurement}

To verify the behaviour of the car with the SW system, we chose a test drive with a constant steering wheel turning angle with a gradual increase in forward speed. The drive was made on the left hand. With the help of the chosen test, it allows to determine the boundary of limit skid

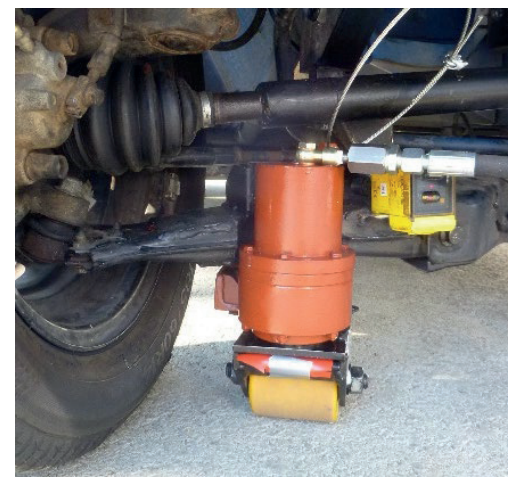

5: SW wheel unit (authors)

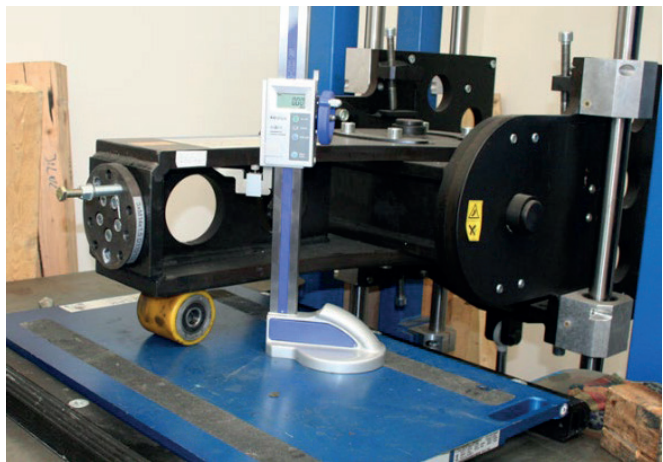

7: Measurement of SW deformation properties on static adhesor (authors) 

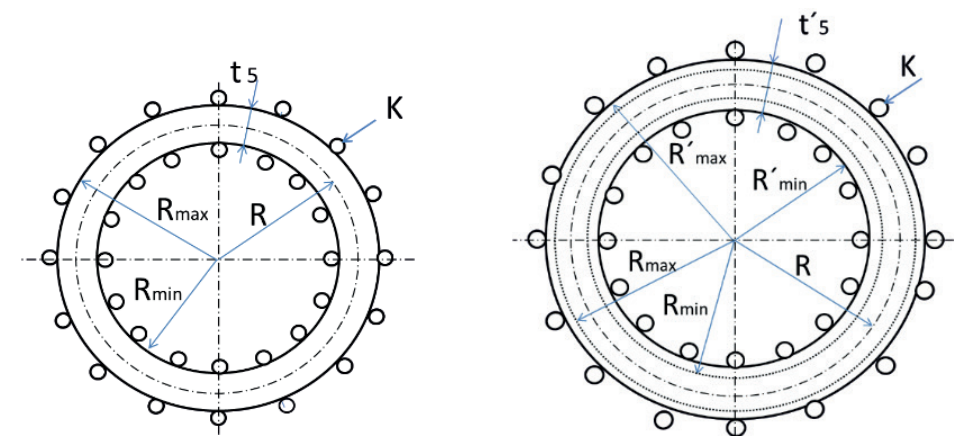

8: Test corridor for test drive (authors)

$t_{5}$ - width of SW circular corridor, $t_{5}$ - width of ASC circular corridor, $R$ - nominal radius of circular corridor, $K$-cone, $R_{\max }$ - outer driving corridor radius, $R_{\min }$ - inner driving corridor radius

relatively easily and with sufficient accuracy. The test corridor is defined by cones in the form of an annulus (Fig. 8). The nominal radius of the test corridor is $\mathrm{R}=10 \mathrm{~m}$. The corridor width is $3 \mathrm{~m}$ for SW test drive; for ASC testing, we increased the corridor width in proportion to the increase in car width due to the ASC frame. During the test, the car speed was gradually and continuously increased so that the longitudinal acceleration does not exceed the value of $a_{x}=0.2 \mathrm{~m} \cdot \mathrm{s}^{-2}$ until the car leaves the defined corridor. Measured variables are car velocity $v$, body tilt angle $\beta_{i}$, longitudinal acceleration $a_{x}$, lateral acceleration $a_{y}$, steering wheel turning angle $\beta_{v}$, car turning velocity $\omega$ and car turning angle $\Psi$.

We conducted a series of verification measurements before starting the measurement in the test corridor or after re-setting the ASC and SW adhesion conditions. The verification measurements are used to verify the functionality of the measuring chain and as a data set for subsequent off-time correction. Correction is necessary in terms of removing any mounting and technical deviations in the installation of the measuring instrument on the car and to eliminate the tilting of the car body when changing the radial response. We selected the verification measurements of all variables in the form of repeated records in the range of seven measurements at a steady ride in a straight line on a track of at least $30 \mathrm{~m}$. The measurements must be repeated for both driving directions to avoid the effect of test road slope. We conducted the experimental measurements for the radial response of car wheels in the amount of 50\%. A 100\% radial response corresponds to driving a classic car supplemented only by the ASC or SW system, when the system is not operating. The car's behaviour is affected only by the added weight of the system.

The maximum size of lateral acceleration $a_{y}$ that can be achieved in the car is given by the adhesion force that the car wheels can transmit in contact with the road. It is assumed that the car will be able to transmit less adhesion force with lightweight external car wheels than with lightweight internal wheels. It is also assumed that the car will pass the driving corridor at a lower speed with a lower adhesion force value.

\section{Processing of Measured Values in Driving Mode}

In compensation measurements, we initially removed outliers and averaged. Thus, we obtained values for off-time correction of longitudinal and lateral acceleration, front, rear, left and right body sections, directional deviation and turning velocity. We removed outliers from of the speed sensor signal that are not related to driving the car.

The current steering wheel turning angle $\beta_{v}$ was determined from the measured signal indicating the extension of the cable from the steering wheel turning angle sensor $l_{l}$ using equation (3).

$\beta_{v}=\frac{180 \times l_{l}}{\pi \times r_{v}}-\beta_{v o}$

Legend: $\beta_{v}$-steering wheel turning angle; $\beta_{v o}$-steering wheel turning angle in verification measurement; $l_{l}$ - cable extension from steering wheel turning angle sensor; $r_{v}$-steering column shaft radius.

We monitor the current position of the car body using ultrasonic distance sensors. The position of the sensors is shown in Fig. 8. The starting point of the body from the road was the position identified during the verification measurements. The final position of the body tilt after the experimental measurements did not return to the initial position due to the hysteresis of rubber parts in the bearing, particularly the chassis system. The body tilt angle is determined by equation (4).

$\beta_{i}=\tan ^{-1}\left(\frac{\left(H_{3 i}-H_{30}\right)-\left(H_{4 i}-H_{40}\right)}{B_{x}}\right)$

Legend: $H_{3 i}$ - vertical distance of the measuring point from the road on the left side of the body at time $t_{i} ; H_{4 i}$ - vertical distance of the measuring point from the road on the right side of the body 


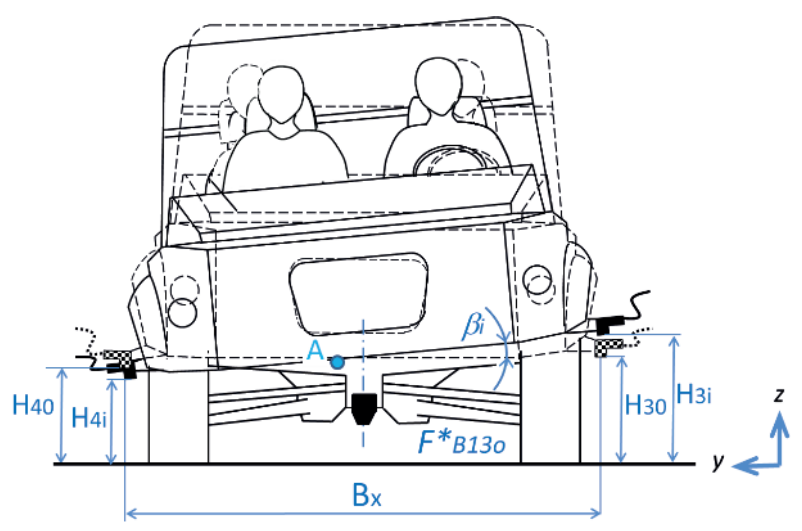

9: Plane model of body tilt: A - body tilt axis (authors)

at time $t_{i} ; H_{30}$ - vertical distance of the measuring point from the road on the left side of the car body corresponding to the steady speed of car movement; $H_{40}$ - vertical distance of the measuring point from the road on the right side of the car body corresponding to the steady speed of car movement; $B_{x}$ - distance between the height sensors in the lateral plane of the car.

Before processing the measured signal from the distance sensors, we removed obvious outliers that were not related to the car movement. We smoothed and eliminated the oscillations not caused by body movement from the waveforms of ultrasonic distance sensors to determine the body tilt. For this purpose, a moving average at time interval $0.2 \mathrm{~s}$ proved successful. When there is no significant effect on the measured waveform. The height sensors were firmly connected to the car body, which is why the sensors were deflected from their vertical position when the body is tilted. Since the amount of body deflection from the equilibrium position does not exceed $5^{\circ}$ (Tesař et al., 2014), the measurement error due to the distance sensor deflection is negligible, and we did not recalculate the distance depending on the body deflection angle from the equilibrium position. We processed the signal from the lateral and longitudinal acceleration sensors only in the form of smoothing the waveform using a moving average at $0.2 \mathrm{~s}$. The initial static body slope is based on the verification measurement, where the value from the verification measurement is subtracted from the currently measured value in the experimental test during off-time signal processing. We processed the signal mapping the turning velocity and the slip angle signal in the form of smoothing the waveforms using a moving average and subsequent off-time correction according to the data obtained during the verification measurements.

The resulting orientation of the measured variables depends on the installation of the sensors on the experimental car. When driving the vehicle on the left hand, the steering wheel turning angle $\beta_{v}$ is negative, and the lateral acceleration $a_{y}$, ay, the body tilt angle $\beta_{i}$ and the position of the right side of the body $H_{40}, H_{4 i}$ are also negative. The angular velocity $\omega$, the slip angle $\varphi$, the position of the left side of the body $H_{3}, H_{3 i}$ and the car turning angle $\Psi$ have positive values. A graphical representation of the car tilt is shown in Fig. 9.

\section{RESULTS}

\section{Test Drive Evaluation}

For a clear comparison of the waveforms, we reported the dependence of the measured variables on time and not on the forward velocity $v$.

It can be seen from the measured longitudinal acceleration waveform (Fig. 10) that a constant speed increase was not ensured during the measured section. It is not possible that the car will skid when starting it under the given conditions of the experiment, so we proceeded to start the vehicle with a higher longitudinal acceleration than at the end of the test. The performance of the car was dosed subjectively (without a control device); thus, it was not possible to achieve a constant acceleration throughout the test. The requirement is that the longitudinal acceleration is constant and less than $0.1 \mathrm{~g}$ in the area before the car is driven out of the corridor, which was achieved in the experiment. The ASC and SW speed waveforms correspond to the theoretical basis and are mutually comparable. The longitudinal acceleration $a_{x}$ corresponds to the theoretical basis and represents the way of starting the car when performing both experimental measurements.

The waveform of velocity $v$ in the experimental measurement is comparable in both cases and is shown in Fig. 11.

The steering wheel angle $\beta$ (Fig. 12) corresponds to the theoretical basis and is comparable in both cases, despite the small corrections in SlideWheel. The waveforms are almost identical in the area just before the limit state.

The variable lateral acceleration $a_{y}$ (Fig. 13) is related to the variable forward acceleration and the steering wheel angle. At a low driving speed, we turned the 


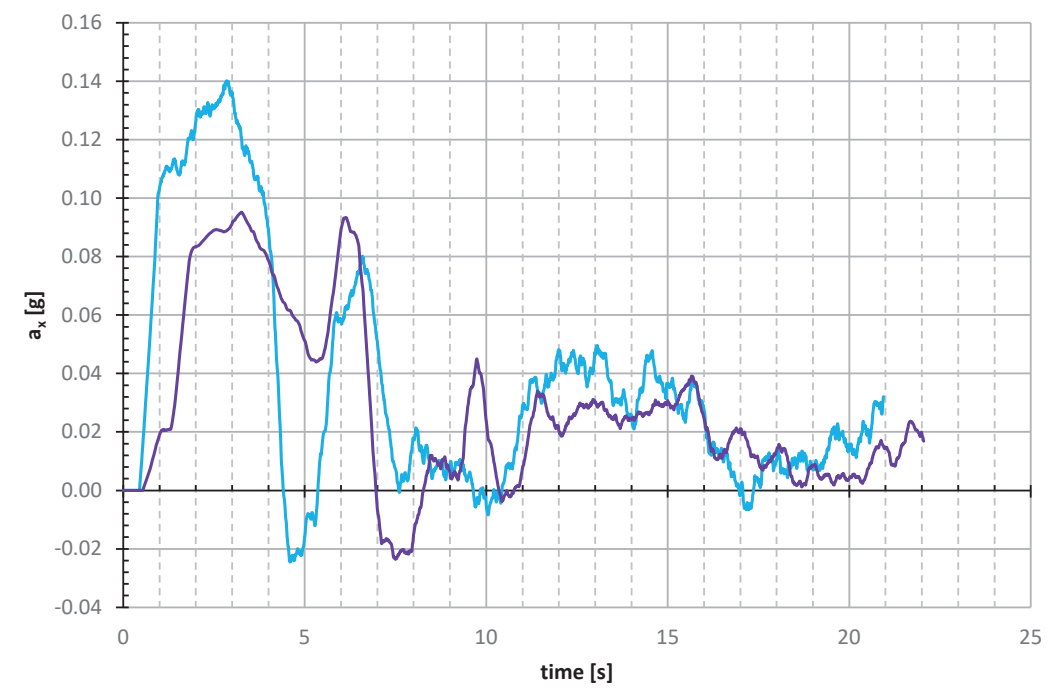

10: Longitudinal acceleration $a_{x^{\prime}}-A S C,-S W$ (authors)

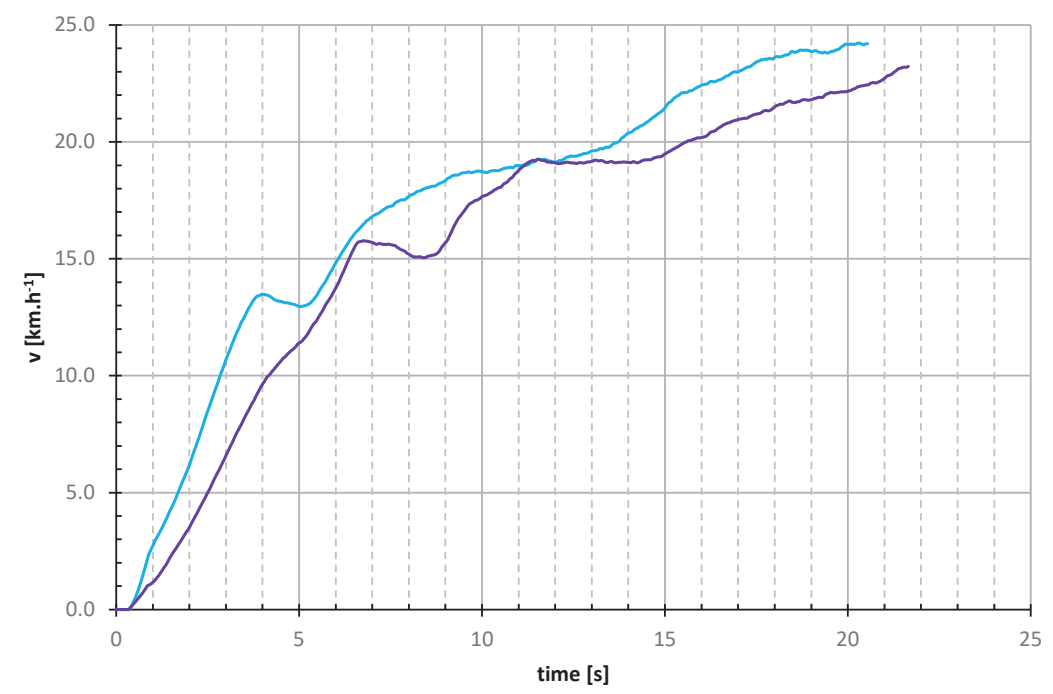

11: Velocity $v,-A S C,-S W$ (authors)

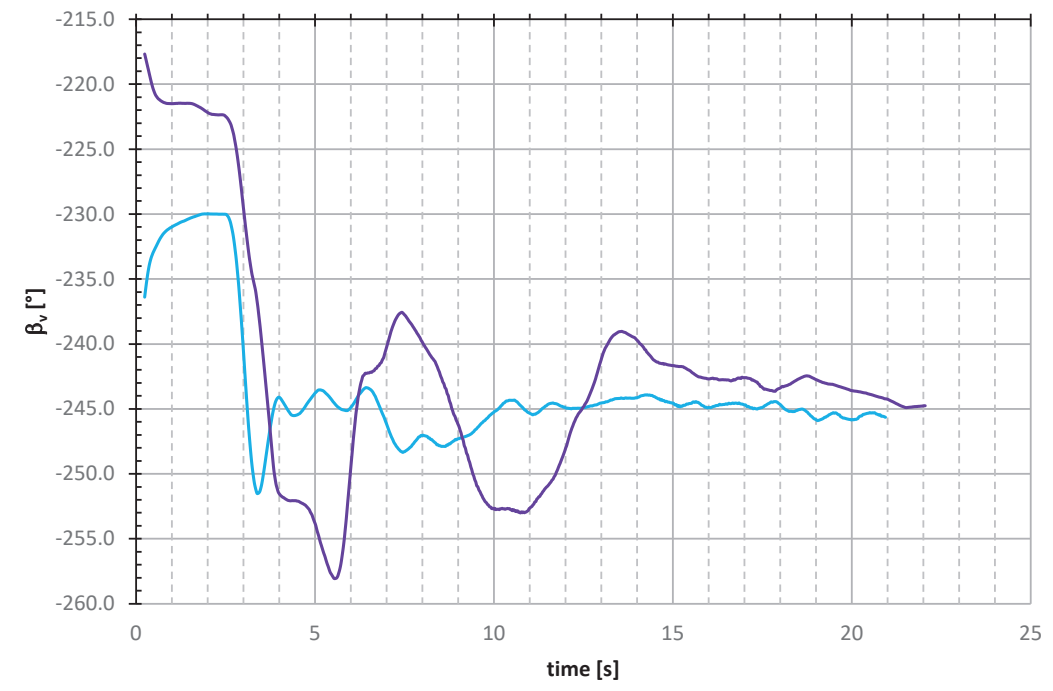

12: Steering wheel angle $\beta_{v}-A S C,-S W$ (authors) 


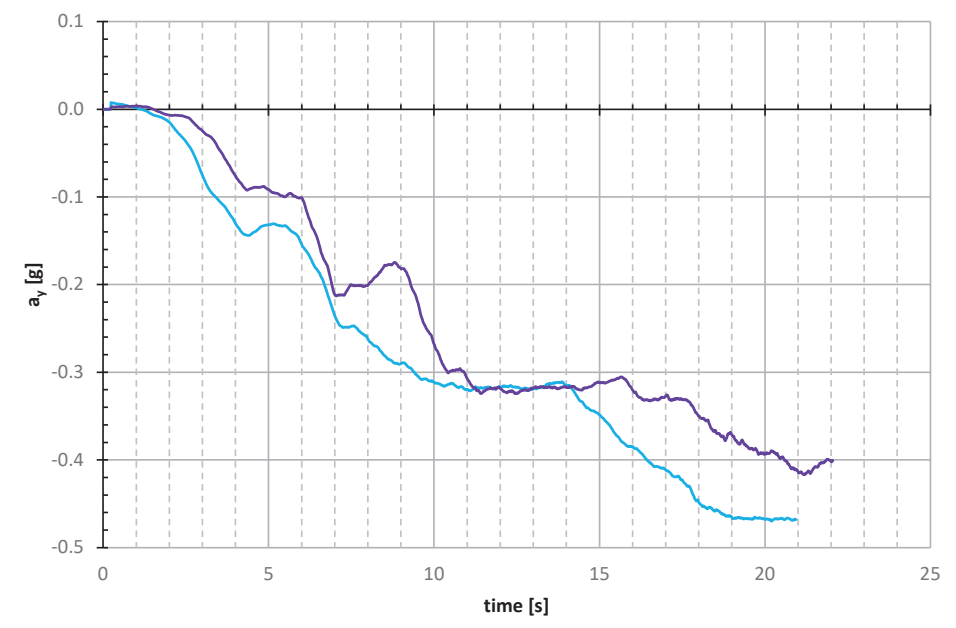

13: Lateral acceleration $a_{y}-A S C,-S W$ (authors)

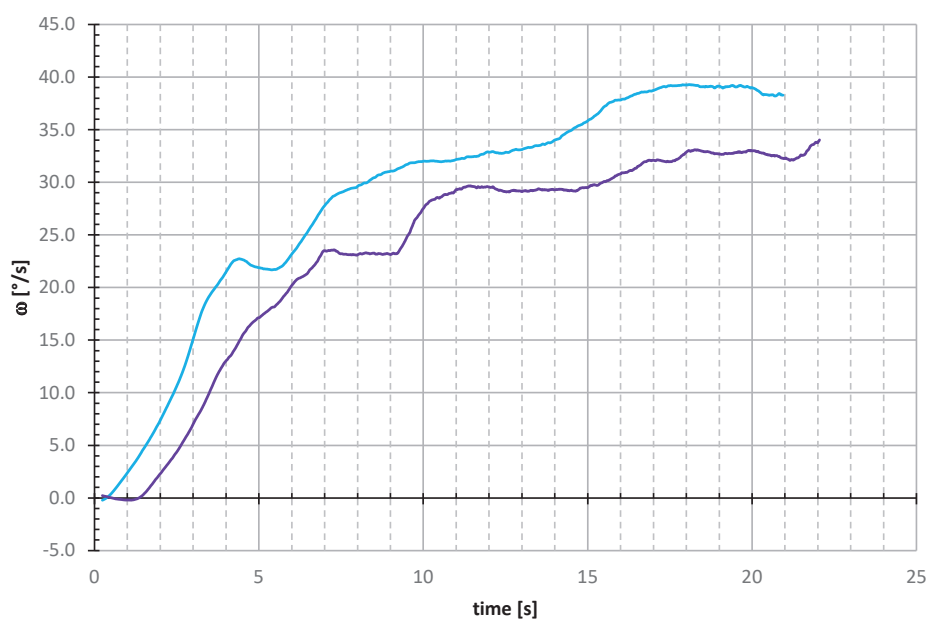

14: Angular velocity $\omega,-A S C,-S W$ (authors)

steering wheel to a position in which the car could drive through the marked-out corridor without a correction by the steering wheel. We then fixed the steering wheel in that position. The $a_{y}$ waveform corresponds to the theoretical basis and is almost identical in both measurements.

The angular velocity $\omega$ (Fig. 14) corresponds to the theoretical basis. In both cases, the angular velocity waveforms are very similar, but it achieves a higher value in case of Alternative SkidCar. The end of the waveform has the opposite direction, so the vehicle is slightly understeering when using both systems for changing the adhesion force. The reason is the design of wheel units, where the tyres have better guidance capability than the SW wheel units.

The slip angle $\varphi$ (Fig. 15) corresponds to the theoretical basis. The sudden increase of the $\varphi$ waveform at the start of the experimental measurement is caused by starting the car having its wheels in lock position. It is slightly higher in the car with Alternative SkidCar than with SlideWheel. The reason is again the design of wheel units, where the tyres have better guidance capability than the SlideWheel wheel units.

The body tilt angle $\beta_{i}$ (Fig. 16) is different. The difference is due to the differences in the design of the systems being compared. Smaller tilt angle in Alternative SkidCar is due to the design and rigidity of the frame. In the SW system, the radial response of the car wheels is reduced through the sprung masses, i.e., the body tilts more easily than in ASC. Here, the Alternative SkidCar frame is larger than the track of the car wheels. The frame is attached to the experimental car body; therefore, the ASC body changes its position to a lesser extent than in the SW system when comparing them.

As the speed of the vehicle increases, the lateral acceleration in the centre of gravity increases, causing the body to tilt and overload the outer wheels and lighten the inner wheels of the car. The body position (height from the road) on the outside approaches the road HP2 and rises on the inside of the body, thus increasing the distance (height from the road) on the distance sensor HL2. As the 


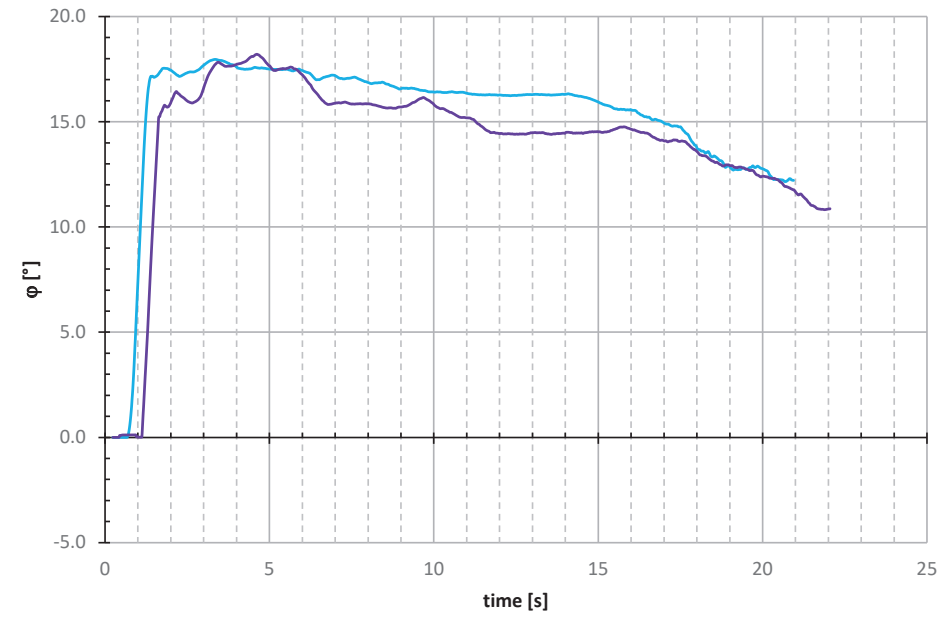

15: Slip angle $\varphi,-A S C,-S W$ (authors)

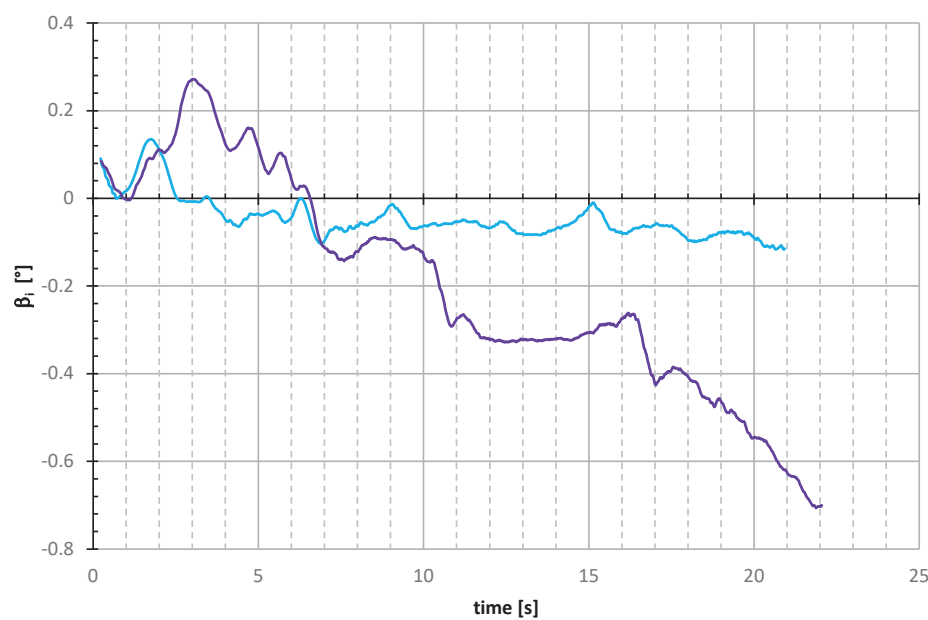

16: Body tilt angle $\beta_{p}-A S C,-S W$ (authors)

speed of the circular track increases, the value of slip angle $\varphi$ decreases gradually. The change in body position with the ASC system is lower than that with the SW system. The reason for this is the Alternative SkidCar frame with a larger track than the car wheel track, while SlideWheel has a smaller track than a classic vehicle, which makes it easier to change its position when comparing the bodies.
It can be seen from the measured waveforms that the Alternative SkidCar system and the SlideWheel system behave in a similar manner at $50 \%$ of the load. The main difference is in the area of body movement where the body with SlideWheel has a significantly larger tilt angle which is closer to the real car movement.

\section{CONCLUSION}

Monitoring the behaviour of a car in relation to driving stability is a relatively widespread area related to vehicle safety. In most cases, real winter conditions or sliding surfaces are used to verify the car's performance under reduced adhesion conditions. The SC system is a device that is predominantly used to teach drivers to handle a vehicle's limit state. There is currently no research that would be interested in objectively monitoring car behaviour with a system for changing the adhesion force. Both ASC and SW are systems that can be used to bring the vehicle to the skid limit when driving safely. This is the primary area of causing a car to skid. The advantage of the systems compared to sliding surfaces is that it is possible to reduce the radial response on any car wheel without affecting the radial response of the other wheels. In this way it is possible to bring the vehicle to any type of skid at a safe speed.

The expectation that both systems behaved similarly was confirmed by experimental measurements at 50\% radial response on car wheels. Compared to ASC, the newly designed SW allows for a more 
natural body tilting and approximates the experiments made on sliding surfaces. Another advantage of SW compared to ASC is less added weight and none of the components of the system exceeding the car plan view. The SW system can also be used for the purpose of driver training. Note that SW should be subjected to further testing and optimization. Both systems can be used for an initial verification of electronic systems for increasing stability and improving road safety in the form of driver training.

\section{REFERENCES}

ALBINSSON, A., BRUZELIUS, F., JACOBSON, B. et al. 2018. Evaluation of vehicle-based tyre testing methods. Proceedings of the institution of mechanical engineers part d-journal of automobile engineering, 233(1): 4-17.

GAO, J., ZHANG, Y., DU, Y. et al. 2019. Optimization of the tire ice traction using combined Levenberg Marquardt (LM) algorithm and neural network. Journal of the Brazilian society of mechanical sciences and engineering, 41: 84-96.

GLOS, J. and SEJKOROVÁ, M. 2016. Tribo diagnostics as and input for the optimization of vehicles preventive maintenance. In: Intelligent Technologies in Logistics and Mechatronics Systems, ITELMS 2016 - Proccedings of the $11^{\text {th }}$ International Conference. Panevéžys, Lithuania, April 28-29, pp. 28-29.

HARUN, M. H., YUNOS, M. R. and AZHARI, M. A. 2016. Validation of Vehicle Model Response with an Instrumented Experimental Vehicle. In: Engineering Technology International Conference (ETIC) 2016. August 5-6, Ho Chi Minh City, Vietnam, pp. 131-136.

JILEK, P., ŠEFČÍK, I., VERNER, J. and BERG, J. 2019. System allowing adhesion force change of road vehicle. In: $18^{\text {th }}$ International Scientific Conference Engineering for Rural Development. May 22-24, Latvia University of Afgriculture, Jelgava, Latvia, pp. 1876-1882.

KOŠTIAL, P., KRMELA, J., FRYDRÝŠEK, K. and RUŽIAK, I. 2012. The Chosen Aspects of Materials and Construction Influence on the Tire Safety. In: HU, N. (Ed.). Composites and Their Properties. Chapter 13. Chorvatsko: InTech, pp. 265-298.

KRMELA, J., BENEŠ, L. and KRMELOVÁ, V. 2014. Tire experiments on static adhesor for obtaining the radial stiffness value. Period. Polytech. Transp. Eng., 42(2): 125-129.

KULIČKA, J. and JILEK, P. 2016. The Fourier Analysis in Transport Application Using Matlab. In: Transport Means proceedings of the international scientific conference. October 5-7, Kaunas, Lietuva, pp. 820-825.

LUCET, E., LENAIN, R. and GRAND, C. 2015. Dynamic path tracking control of a vehicle on slippery terrain. Control engineering practice, 42: 60-73.

MAREK, V. and ČUPERA, J. 2016. Data Mining of Vehicle Control Units. MendelNet, 23: 944-948.

RIEVAJ, V., VRABEL, J., SYNAK, F. et al. 2018. The effects of vehicle load on driving characteristics. Advances in science and technology-research journal, 12(1): 142-149.

SEJKOROVÁ, M., HURTOVÁ, I., GLOS, J. and POKORNÝ, J. 2017. Definition of a motor oil change interval for high volume diesel engines based on its current characteristics assessment. Acta Universitatis Agriculturae et Silviculturae Mendelianae Brunensis, 65(2): 481-490.

TESAŘ, M., JILEK, P. and POKORNÝ, J. 2014. Experimentální měření s využitím sklopné plošiny. In: XI. mezinárodní konference kateder dopravních, manipulačních, stavebních a zemédělských strojů. Ostrava: Institut dopravy Fakulty strojní VŠB - TU Ostrava, pp. 1-4.

ŠARKAN, B., SKRÚCANÝ, T., SEMANOVÁ, Š. et al. 2018. Vehicle coast-down method as a tool for calculating total resistance for the purposes of type-approval fuel consumption. Scientific Journal of Silesian University of Technology. Series Transport, 98: 161-172.

VERNER, J. and SEJKOROVÁ, M. 2018. Comparison of CVS and PEMS measuring devices used for stating CO2 exhaust emissions of light-duty vehicles during WLTP testing procedure. In: $17^{\text {th }}$ International Scientific Conference Engineering for Rural Development, ERD 2018. Jeglava, May 23-25, pp. 20542059.

Petr Jilek: petr.jilek@upce.cz

Jan Němec: nemec.jan@upce.cz 